\title{
Birth outcomes by level of obstetric care in Finland: a catchment area based analysis
}

\author{
Kirsi Viisainen, Mika Gissler, Elina Hemminki
}

\begin{abstract}
Study objective - To study whether hospitals of different levels are equally safe places to give birth in a regionalised system of care.

Design - This was a population based, cross sectional survey comparing birth outcomes in nationwide catchment areas of different levels of hospital care. All women and low risk women were examined separately.

Setting and subjects - The study population comprised all women who gave birth in Finland in 1987-88. The data were obtained from the Finnish Medical Registry, complemented by official data. Main results - No statistically significant differences were found in crude or birthweight specific perinatal mortality rates between the catchment areas, nor did the other outcomes studied favour tertiary care compared with other levels of care in the area based analysis.

Conclusions - In a regionalised system of birth care with a proper referral system, small local hospitals are as safe places to give birth as tertiary care hospitals.
\end{abstract}

( $(\mathcal{F}$ Epidemiol Community Health 1994;48:400-405)

It has been argued that births should be moved away from small primary level places of care because these hospitals and maternity centres are unsafe places to give birth. ${ }^{1}$ The question of safety has been presented as an argument for closing down small maternity hospitals in various countries and it has provoked numerous studies about the relative safety of different places of birth. ${ }^{1}$

The safety of different levels of hospitals has been examined in studies that compare perinatal outcomes between hospitals. These studies seem to be quite uniform in their conclusions about the benefits of tertiary care hospitals with facilities for neonatal intensive care for low and very low birthweight babies. ${ }^{2-5}$ Yet, the benefits of tertiary level birth care for normal birthweight babies are not so clear cut. Studies have indicated that normal birthweight babies either tend to do better in small primary level hospitals in regionalised systems of care, ${ }^{4,6}$ or as well as in tertiary level care. ${ }^{57}$

Because of medical and self referral of high risk cases to tertiary level care, hospitals cannot be directly compared. All comparisons of levels of hospital care have to deal with the problem of patient selection, either by medical, social, or geographical reasons or simply because of women's preference. The most common method for overcoming the selection bias by medical referral has been to analyse outcomes in relation to birthweight. Although the use of birthweight specific perinatal mortality rates has potential biases, ${ }^{8}$ these rates have been used in several studies as indicators of quality of birth and pregnancy care. ${ }^{4-7}$ All potential medical risks, however, cannot be detected by birthweight alone. Other methods for overcoming selection bias are retrospective risk scoring ${ }^{9}$ and limiting the study population to a low risk group only..$^{10}$ In this study we used geographical catchment areas rather than hospital patient populations as the primary basis of analysis, in order to overcome the problem of patient selection. In a regionalised system this approach provides a means of comparing the performance of the maternity care system in areas with different first choice levels of care.

Finland has a regionalised system of obstetric care. Antenatal care is given in special out of hospital maternity centres run by local municipalities. Care is given by public health nurses and physicians, who are usually general practitioners. Suspected high risk pregnancies are sent for specialist consultation in hospital antenatal clinics. ${ }^{11}$ Virtually all deliveries take place in publicly financed hospitals. As a rule, hospitals have geographical catchment areas for low risk births, although these sometimes overlap. Thus, women are initially expected to deliver in the hospital within or closest to their municipality, although no official booking is done. Some municipalities have more than one hospital close by, which gives women the possibility to choose according to preference. Travelling to another part of the country for birth is rare. Detected high risk cases are referred for birth to an appropriate level of care. This decision is usually made during pregnancy but referrals during birth also occur.

At all levels, births are primarily supervised by midwives but obstetricians are "in charge" in all other levels, except in community hospitals, in which general practitioners have responsibility.

All women have access to free antenatal care, and birth in a hospital is heavily subsidised. As in other countries with regionalised care, several small primary level hospitals have closed down their maternity units in the past decades. The number of hospitals that provide maternity care has fallen from 64 in $1976^{12}$ to 49 in 1991 (unpublished data - Finish Medical Birth Registry). 


\section{Methods}

The study population comprised all women who gave birth in Finland in 1987-88 $(n=123065)$. Data on births were obtained from the Finnish Medical Birth Registry, which is a computerised database of all births that take place in Finland. These included the location of each birth, the place of residence of the mother, and the birthweight of all live and stillborn infants over 22 weeks of gestation or over $500 \mathrm{~g}$ in weight. This information was complemented by information about live births, still births, and neonatal deaths (under 28 days of age) from the official data for 1987 88. In cases in which there was conflict about the living status of the infant, official data were relied on, and in cases in which the neonate died in a hospital that was different to the one that he or she had been born in, the deaths were attributed to the hospital of birth. Data on mothers' education were obtained by a record linkage to the National Education Registry. Educational data were only available for 1987. (For more details on the Finnish Birth Registry, see $^{1314}$.) Details on the urbanism of the municipalities was obtained from published statistics. ${ }^{15}$

Finnish maternity hospitals $(n=53)$ were classified into four mutually exclusive levels of care using the official administrative levels as a basis. Information on staffing and equipment of hospitals was obtained from unpublished data collected for a previous survey. ${ }^{16}$ The classification of one community hospital and of two local hospitals was changed because their staffing, equipment, and volume of patients resembled the next higher administrative level of care more closely than their original classification. The classification of levels of care was as follows (table 1).

LEVEL $1 \mathrm{~A}$

There were five community hospitals which had maternity care facilities for low risk pregnancies. These facilities are situated in remote areas and are generally run by general practitioners. One of them has a consultant obstetrician. There are no special care units for neonates.

LEVEL $1 \mathrm{~B}$

Twenty five of the hospitals were classified as primary level hospitals. These were 24 local hospitals and one big community hospital maternity unit. These are obstetric units led by a consultant obstetrician with no teaching function. These hospitals are equipped mainly for

Table 1 Characteristics of the maternity units in relation to level of care

\begin{tabular}{|c|c|c|c|c|}
\hline & \multicolumn{4}{|c|}{ Catchment area } \\
\hline & Level 3 & Level 2 & Level $1 b$ & Level $1 a$ \\
\hline $\begin{array}{l}\text { No of hospitals } \\
\text { Staff of maternity units include: }\end{array}$ & 5 & 18 & 25 & 5 \\
\hline Obstetricians & 5 & 18 & 25 & 1 \\
\hline Specialising obstetricians & 5 & 9 & 3 & 0 \\
\hline Other physicians & 0 & 4 & 10 & 5 \\
\hline Paediatrician available during delivery & 5 & 18 & 15 & 0 \\
\hline $\begin{array}{l}\text { Average annual number of births per hospital, } \\
1987-88\end{array}$ & 3478 & 1505 & 614 & 113 \\
\hline
\end{tabular}

normal healthy newborns but are able to stabilise the condition of sick infants for transport to another centre. Some units have a paediatric department, some do not. Some have a newborn special care unit for short term surveillance. In these hospitals obstetricians are generally not on premises during on-call hours.

\section{LEVEL 2}

Eighteen of the maternity hospitals were classified as secondary level. Sixteen of these are regional hospitals which serve as teaching units for specialisation. Two metropolitan hospitals that are administratively local hospitals were also classified as level 2 because they are teaching hospitals and their staffing and equipment are similar to those in regional hospitals. Level 2 hospitals vary in size and equipment, but all have obstetricians on the premises 24 hours a day and paediatric departments and newborn special care units adjacent to them. Some have intensive care cots for sick newborns.

\section{LEVEL 3}

Five university teaching hospitals were classified as tertiary care units. These hospitals are among the largest maternity units in the country and are equipped for neonatal intensive care. A resident neonatologist is on-call in three university hospitals, in others there is a resident paediatrician.

Birth registry data on the residence of the mother were used for defining the catchment areas for each level of care. A first choice hospital of birth care was determined for each of the 460 Finnish municipalities (the lowest level administrative unit). This was a hospital in which more than two thirds of all births in that municipality took place in 1987 . The births in municipalities with the same first choice level of birth care were pooled to form four nationwide catchment areas for different levels of care. There were 56 municipalities with 17196 births ( $14 \%$ of all births) for which the first choice hospital could not be defined, as births were almost equally distributed between two or more hospitals of different levels. Births in these municipalities were treated as a separate group in the analysis (mixed).

The coverage of the catchment areas thus formed was assessed by determining what proportion of mothers primarily served by each level of care actually gave birth at that level. All the catchment areas had more than $69 \%$ of their births in the local level of care (table 2). The best coverage was found in the areas served primarily by level 3 hospitals and the lowest in areas served by community hospitals (level 1b). Level 2 and level $1 \mathrm{~b}$ hospitals had similar coverage rates. There were 1186 births $(1 \%)$ for which the residence of the mother was not known. These were excluded, and thus the final study population in the catchment area analysis was 121879 women who gave birth.

Eight potentially confounding background 
Table 2 Distribution of births in different places of birth by catchment areas (1987-88)

\begin{tabular}{|c|c|c|c|c|c|c|}
\hline \multirow[b]{2}{*}{ Actual place of birth } & \multicolumn{6}{|c|}{ Catchment area $(\%)$} \\
\hline & Level 3 & Level 2 & Level $1 b$ & Level $1 a$ & Mixed & Total \\
\hline $\begin{array}{l}\text { Level } 3 \\
\text { Level } 2 \\
\text { Level 1b } \\
\text { Level 1a } \\
\text { Not known }\end{array}$ & $\begin{array}{c}(\mathrm{n}=22529) \\
91 \cdot 5 \\
2 \cdot 6 \\
4.5 \\
0.0 \\
1 \cdot 4\end{array}$ & $\begin{array}{c}(\mathrm{n}=61215) \\
8.8 \\
87.9 \\
1.6 \\
0.0 \\
1.7\end{array}$ & $\begin{array}{c}(n=19776) \\
8 \cdot 3 \\
5 \cdot 6 \\
84 \cdot 4 \\
0 \cdot 0 \\
1 \cdot 6\end{array}$ & $\begin{array}{c}(\mathrm{n}=1163) \\
6 \cdot 9 \\
20 \cdot 0 \\
1.4 \\
69 \cdot 4 \\
2.3\end{array}$ & $\begin{array}{l}(\mathrm{n}=17196) \\
38 \cdot 6 \\
26 \cdot 6 \\
31.7 \\
1.6 \\
1.5\end{array}$ & $\begin{array}{c}(\mathrm{n}=123065) \\
28.3 \\
49 \cdot 1 \\
19.9 \\
0.9 \\
1.8\end{array}$ \\
\hline & 100.0 & $100 \cdot 0$ & $100 \cdot 0$ & $100 \cdot 0$ & $100 \cdot 0$ & $100 \cdot 0$ \\
\hline
\end{tabular}

Statistically significant values in italics.

characteristics of the mother were examined within the catchment area populations (table 3). The age distribution, marital status, and proportion of primiparae were similar for the other catchment areas, but women in level la (community hospital) areas were less likely to be married and less likely to be primiparae than in other catchment areas. They were also more likely to have had three or more previous births, and, similarly, previous stillbirths were slightly more common in this area. The percentage of mothers with higher education was greater in areas of level 2 and 3 than in level 1 areas. Municipalities in which $80 \%$ or more of the population lived in built up areas were classified as urban. ${ }^{16}$ Women in levels 3 and 2 were much more often urban than women in levels $1 \mathrm{~b}$ and 1a. The proportions of smokers were relatively similar; however, somewhat

Table 3 Background characteristics of women giving birth in relation to catchment areas

\begin{tabular}{|c|c|c|c|c|c|}
\hline \multirow[b]{2}{*}{ Characteristics } & \multicolumn{5}{|c|}{ Catchment area $(\%)$} \\
\hline & Level 3 & Level 2 & Level $1 b$ & Level la & Mixed \\
\hline \multicolumn{6}{|l|}{ All women: } \\
\hline Age $20-34$ y & 83.5 & $83 \cdot 4$ & $83 \cdot 8$ & $84 \cdot 4$ & 83.7 \\
\hline Married & $81 \cdot 0$ & $78 \cdot 0$ & $79 \cdot 0$ & $70 \cdot 4$ & $79 \cdot 3$ \\
\hline Primiparae & $38 \cdot 4$ & $40 \cdot 0$ & $37 \cdot 0$ & $31 \cdot 6$ & $41 \cdot 0$ \\
\hline $3+$ births* & $8 \cdot 8$ & $7 \cdot 4$ & $8 \cdot 8$ & $14 \cdot 7$ & $6 \cdot 9$ \\
\hline Previous stillbirths & $1 \cdot 7$ & $1 \cdot 3$ & $1 \cdot 3$ & 1.9 & $1 \cdot 6$ \\
\hline Educated & $15 \cdot 5$ & $17 \cdot 0$ & $11 \cdot 4$ & $8 \cdot 2$ & $14 \cdot 8$ \\
\hline Urban & $61 \cdot 7$ & $59 \cdot 4$ & $44 \cdot 4$ & 0.0 & $59 \cdot 8$ \\
\hline Smokers & $12 \cdot 8$ & $15 \cdot 4$ & $14 \cdot 8$ & $15 \cdot 0$ & $15 \cdot 6$ \\
\hline \multirow{2}{*}{\multicolumn{6}{|c|}{ Low risk women: }} \\
\hline & $81 \cdot 8$ & $78 \cdot 9$ & $80 \cdot 0$ & $70 \cdot 3$ & $80 \cdot 3$ \\
\hline Primiparae & $41 \cdot 1$ & $42 \cdot 2$ & $39 \cdot 0$ & $32 \cdot 8$ & $43 \cdot 4$ \\
\hline $3+$ births* & $5 \cdot 5$ & $4 \cdot 7$ & $5 \cdot 6$ & $10 \cdot 0$ & $4 \cdot 6$ \\
\hline Educated $\dagger$ & $15 \cdot 2$ & $16 \cdot 0$ & $10 \cdot 7$ & $7 \cdot 4$ & $14 \cdot 3$ \\
\hline Urban+ & $62 \cdot 3$ & $59 \cdot 7$ & $44 \cdot 8$ & $0 \cdot 0$ & $60 \cdot 4$ \\
\hline Smokers & 12.5 & $15 \cdot 2$ & $14 \cdot 7$ & $15 \cdot 1$ & $15 \cdot 3$ \\
\hline
\end{tabular}

* Three or more previous births.

+ More than 12 years of education, data for 1987 only.

$\ddagger$ Women lived in municipalities in which $80 \%$ or more of the population live in built up areas.

Table 4 Infant outcomes in relation to the actual place of birth, 1987-88 (hospital based analysis)

\begin{tabular}{lcccc}
\hline \multicolumn{5}{c}{ Place of birth $(\%)$} \\
\cline { 2 - 5 } Outcome & Level 3 & Level 2 & Level 1b & Level 1a \\
\hline Low birthweight & $6 \cdot 8$ & $3 \cdot 4^{* * *}$ & $1 \cdot 6^{* * *}$ & $1 \cdot 1^{* * *}$ \\
Preterm & $10 \cdot 0$ & $5 \cdot 2^{* * *}$ & $3 \cdot 2^{* * *}$ & $2 \cdot 6^{* * *}$ \\
Low Apgar score & $5 \cdot 2$ & $3 \cdot 3^{* * *}$ & $3 \cdot 1^{* * *}$ & $2 \cdot 4^{* * *}$ \\
Transfer to another unit & $7 \cdot 4$ & $6 \cdot 9^{* * *}$ & $3 \cdot 4^{* * *}$ & $4 \cdot 1^{* * *}$ \\
Perinatal mortality $(/ 1000)$ & & & & \\
Crude & $13 \cdot 5$ & $6 \cdot 5^{* * *}$ & $5 \cdot 0^{* * *}$ & $4 \cdot 4^{* * *}$ \\
Birthweight specific $(\mathrm{g}) \leqslant 1499$ & $376 \cdot 5$ & $508 \cdot 5^{* * *}$ & $857 \cdot 1^{* * *}$ & $1000 \cdot 0^{* * *}$ \\
1500-2499 & $61 \cdot 4$ & $43 \cdot 7^{* * *}$ & $68 \cdot 3^{* * *}$ & $83 \cdot 3^{* * *}$ \\
$\geqslant 2500$ & $3 \cdot 1$ & $2 \cdot 1^{* *}$ & $2 \cdot 3$ & $2 \cdot 7$ \\
\hline
\end{tabular}

${ }^{* * *} \mathrm{p}<0.001,{ }^{* *} \mathrm{p}<0.01,{ }^{*} \mathrm{p}<0.05$.

Statistical testing is done against level 3. In tables 4,5 , and 6 low birthweight $=<2500$ preterm $=$ gestational age $<37$ weeks; low Apgar score $=<7$ at one minute; transfer $=$ infant transferred to surveillance, special or intensive care, in same or other hospital, before 7 days of age. fewer women in level 3 smoked during pregnancy.

A low risk group was defined in order to control further for potential differences in the medical risk status of the populations in the catchment areas. The selected low risk group included women who were 20-34 years of age, had a singleton birth, and had no earlier stillbirths. The distributions of background characteristics of the mother in this selected low risk group were found to be similar to the characteristics of all women in the study (table 3).

The following variables were used as infant outcome measures: low birthweight (below $2500 \mathrm{~g}$ ), prematurity (less than 37 weeks of gestation), crude and birthweight specific perinatal mortality rates, low one minute Apgar score (less than 7), and the rate of newborns needing transfer either to newborn surveillance, to special care unit, or to newborn intensive care. The Caesarean section rate was used as an intervention outcome. Statistical significance of the differences in the infant outcomes between areas were tested by $t$ test and $\chi^{2}$ test using level 3 as the reference group.

Multivariate analyses were used to adjust for differences in mothers' background characteristics in 1987. The data from 1988 could not be used here because education data were only available for 1987. In the logistic regression analysis undertaken for all women and for low risk women, the following background variables were first entered in the model: age (no information $=25$ years), marital status (married, cohabiting, unmarried, widowed, divorced, no information), education (less than $9,10-11,12,13$ years, or no information), previous pregnancies (no information $=1$ ) and previous stillbirths (no information $=0$ ). In the next step, the catchment area was entered in the model. To calculate odds ratios, the area of level 3 hospitals was used as the reference.

\section{Results}

\section{HOSPITAL BASED RESULTS}

The outcomes were first analysed by the actual place of birth (table 4). The results showed that low birthweight and preterm infants were concentrated in level 3 hospitals. Equally, low one minute Apgar scores and the rate of children needing surveillance or special care were both significantly more common in level 3 than in other hospitals.

As would be expected, the crude perinatal mortality rate was significantly higher in level 3 hospitals than in other hospitals. The birth- 
Table 5 Infant outcomes and Caesarean sections in relation to catchment areas, 1987-88

\begin{tabular}{|c|c|c|c|c|c|}
\hline \multirow[b]{2}{*}{ Outcomes } & \multicolumn{5}{|c|}{ Catchment areas $(\%)$} \\
\hline & Level 3 & Level 2 & Level $1 b$ & Level 1a & Mixed \\
\hline $\begin{array}{l}\text { All births: } \\
\text { Low birthweight } \\
\text { Preterm } \\
\text { Low Apgar score } \\
\text { Transfer to other unit } \\
\text { Caesarean births }\end{array}$ & $\begin{array}{r}4 \cdot 1 \\
6 \cdot 7 \\
4 \cdot 0 \\
6 \cdot 0 \\
12 \cdot 9\end{array}$ & $\begin{array}{l}3 \cdot 9 \\
5 \cdot 8^{* * *} \\
3 \cdot 7^{* *} \\
6 \cdot 7^{* * *} \\
14 \cdot 2^{* * *}\end{array}$ & $\begin{array}{l}3 \cdot 8 \\
6 \cdot 0^{* *} \\
3 \cdot 8 \\
5 \cdot 7 \\
16 \cdot 3^{* * *}\end{array}$ & $\begin{array}{l}3 \cdot 2 \\
4 \cdot 6^{* *} \\
3 \cdot 7 \\
5 \cdot 7 \\
13 \cdot 0\end{array}$ & $\begin{array}{r}4 \cdot 2 \\
6.5 \\
3.7 \\
5 \cdot 4 \\
15 \cdot 8\end{array}$ \\
\hline $\begin{array}{l}\text { Perinatal mortality } \\
\text { Crude } \\
\text { Birthweight specific (g) } \\
\quad \leqslant 1499 \\
1500-2400 \\
\geqslant 2500\end{array}$ & $\begin{array}{r}9.0 \\
508 \cdot 4 \\
56.0 \\
2.5\end{array}$ & $\begin{array}{r}8.4 \\
426 \cdot 4 \\
52 \cdot 7 \\
2.4\end{array}$ & $\begin{array}{r}9 \cdot 3 \\
438 \cdot 6 \\
66 \cdot 2 \\
2 \cdot 7\end{array}$ & $\begin{array}{r}7 \cdot 7 \\
571 \cdot 4 \\
33 \cdot 3 \\
2 \cdot 7\end{array}$ & $\begin{array}{r}7 \cdot 8 \\
391 \cdot 3 \\
45 \cdot 3 \\
1.9\end{array}$ \\
\hline $\begin{array}{l}\text { Low risk pregnancies: } \\
\text { Low birthweight } \\
\text { Preterm } \\
\text { Low Apgar score } \\
\text { Transfer to other unit } \\
\text { Caesarean births }\end{array}$ & $\begin{array}{r}3.0 \\
5.2 \\
3.8 \\
5.1 \\
11.9\end{array}$ & $\begin{array}{c}2 \cdot 8 \\
4 \cdot 6^{* * *} \\
3 \cdot 3^{* *} \\
5 \cdot 9^{* * *} \\
12 \cdot 6^{* *}\end{array}$ & $\begin{array}{c}2 \cdot 6^{*} \\
4 \cdot 6^{* *} \\
3 \cdot 6 \\
4 \cdot 9 \\
14 \cdot 7^{* * *}\end{array}$ & $\begin{array}{r}2 \cdot 2 \\
4 \cdot 0 \\
3 \cdot 3 \\
5 \cdot 6 \\
13 \cdot 1\end{array}$ & $\begin{array}{c}3 \cdot 2 \\
5 \cdot 3 \\
3 \cdot 5 \\
4 \cdot 5 \\
14 \cdot 3^{* * *}\end{array}$ \\
\hline $\begin{array}{l}\text { Perinatal mortality }(/ 1000) \text { : } \\
\text { Crude } \\
\text { Birthweight specific }(\mathrm{g}) \\
\quad \leqslant 1499 \\
1500-2499 \\
\geqslant 2500\end{array}$ & $\begin{array}{r}7 \cdot 6 \\
536 \cdot 8 \\
70 \cdot 0 \\
2 \cdot 6\end{array}$ & $\begin{array}{r}6 \cdot 7 \\
410 \cdot 4 \\
57 \cdot 3 \\
2 \cdot 3\end{array}$ & $\begin{array}{r}7 \cdot 5 \\
478 \cdot 7 \\
85 \cdot 2 \\
2.5\end{array}$ & $\begin{array}{r}7 \cdot 3 \\
600 \cdot 0 \\
62 \cdot 5 \\
2 \cdot 2\end{array}$ & $\begin{array}{r}7 \cdot 1 \\
438 \cdot 1 \\
56 \cdot 0 \\
1 \cdot 9\end{array}$ \\
\hline
\end{tabular}

*** $\mathrm{p}<0.001,{ }^{* *} \mathrm{p}<0.01,{ }^{*} \mathrm{p}<0.05$

See footnotes table 3 .
When adjustment was done for mothers' background characteristics the results remained similar (table 6). Only the difference in rates of low one minute Apgar scores became more significant between levels 3 and $1 b$.

\section{CATCHMENT AREA BASED RESULTS, LOW RISK} WOMEN

When analysis was done using a selected low risk group of women, the overall rates of low birthweight, preterm infants, low Apgar scores, and infants needing transfer were lower than for all women, yet the differencess between the areas stayed similar (table 5). As could be expected, crude perinatal mortality rates for the low risk group were lower than for all births across the catchment areas. Differences in birthweight specific mortality rates between areas for the low risk women remained in the same proportions as for all women. Some of the birthweight specific mortality rates were higher, however, for the low risk group than for all women. There were fewer Caesarean sections in each catchment area, but no difference emerged in the distribution of Caesarean births between areas in comparison with all births. Adjustment for differences in the mother's background characteristics did not change the outcomes for low risk women (adjusted data not shown).

\section{Discussion}

The study results show that there were no striking differences in birth outcomes in different regions of Finland with a different level of first choice maternity hospital. This indicates that in a system of regionalised care, infants have a similar rate of survival and their condition is similar whether their mother resides in an area primarily served by a small local birth unit or in one served by a university teaching hospital. A functioning referral system seems to ascertain that detected high risk pregnant women are sent to the appropriate level of care. In Finland the detection rate also seems high - the numbers of low birthweight infants born in level $1 \mathrm{a}$ and $1 \mathrm{~b}$ hospitals are small.

Earlier comparative studies between birth care in different levels of hospitals have shown that the smallest babies do better in tertiary care but normal birthweight babies benefit from care in smaller hospitals. ${ }^{46}$ In our hospital based analysis, the survival rate for very low and low birthweight infants was clearly best in tertiary care hospitals, but in the nor-

Table 6 Odds ratios (95\% CI) of infant outcomes (all births) in relation to catchment areas after adjustment for differences in mother's background characteristics in 1987, logistic regression analysis

\begin{tabular}{|c|c|c|c|c|c|}
\hline \multirow[b]{2}{*}{ Outcomes } & \multicolumn{5}{|c|}{ Catchment areas } \\
\hline & Level 3 & Level 2 & Level $1 b$ & Level 1a & Mixed \\
\hline $\begin{array}{l}\text { Low birthweight } \\
\text { Preterm } \\
\text { Low Apgar score } \\
\text { Transfer to other unit } \\
\text { Crude perinatal mortality }(/ 1000)\end{array}$ & $\begin{array}{l}1 \cdot 0 \\
1 \cdot 0 \\
1 \cdot 0 \\
1 \cdot 0 \\
1 \cdot 0\end{array}$ & $\begin{array}{l}0.90(0.81,1.01) \\
0.81(0.74,0.89) \\
0.83(0.74,0.92) \\
1.17(1.06,1.28) \\
0.92(0.72,1.16)\end{array}$ & $\begin{array}{l}0.92(0.80,1.06) \\
0.85(0.76,0.95) \\
0.87(0.75,1.00) \\
0.91(0.81,1.02) \\
1.02(0.76,1.36)\end{array}$ & $\begin{array}{l}0.65(0.38,1.10) \\
0.53(0.34,0.83) \\
0.75(0.46,1.22) \\
0.75(0.50,1.12) \\
0.58(0.18,1.86)\end{array}$ & $\begin{array}{l}0.99(0.86,1 \cdot 14) \\
0.97(0.86,1.09) \\
0.84(0.76,0.98) \\
0 \cdot 87(0.76,0.98) \\
0.96(0.71,1.30)\end{array}$ \\
\hline
\end{tabular}

The statistically significant ( $5 \%$ level of significance) differences of odds ratios between the level studied and level 3 are in italics. 
mal birthweight group the difference for the benefit of the smallest hospitals was not as clear as has been found in some earlier studies. ${ }^{45}$ Level 2 hospitals, however, had a significantly better perinatal mortality rate than level 3 hospitals.

In the area based analysis, crude and birthweight specific perinatal mortality rates showed no statistically significant difference between catchment areas of different levels of hospitals. It is interesting to note that level 2 areas had better survival rates for all birthweight groups than level 3 areas, although the differences were not significant.

Although most outcomes were very similar across the catchment areas, in the area served by level 3 hospitals, newborns were more likely to be preterm and to have low birthweight. This might reflect a more active policy of induction or performing Caesarean sections before term in level 3 hospitals. The active policy may be due to differences in opinions or to security offered by the availability of high quality intensive newborn care in level 3 hospitals. Yet, the Caesarean section rates were higher for areas served by primary level hospitals (level $1 \mathrm{~b}$ ). The differences in Caesarean section rates between catchment areas might indicate differences in local practice styles. A recent area based study of Caesarean rates in Finland showed great variation between hospitals of the same level of care (E. Hemminki, unpublished data).

The higher rate of preterm births in catchment areas served by level 3 hospitals may also be due to population differences in the different catchment areas, although table 3 does not suggest this. Our previous analyses from Finland have shown that premature birth is related to marital status, age, education, parity, and smoking. ${ }^{1417}$ But there may have been population differences in risk factors not measured in this study - for example, work conditions.

This study, like others needing a large number of births, is limited by the restrictions of a ready registry database. In general, the validity of the data of the Finnish Medical Birth Registry has been shown to be good. ${ }^{18}$ The variables used in this study were chosen by their shown validity, which limited the number of variables that could be used for outcomes. Because of poor validity, diagnoses could not be used for determining the morbidity of the mother or infant. Even though it is known that the 5-minute Apgar score is a better predictor of the infant's condition, only the 1-minute score could be used in this study. Five minute scores were lacking for $20 \%$ of the newborn infants and the internal validity study showed them to be less accurately reported in the registry than 1 -minute scores. ${ }^{19}$ Also, medical procedures, other than Caesarean sections, were too poorly recorded to be used in this study. The distribution of lethal congenital malformations between the areas could not be verified from the registry, but according to an earlier, Swedish, area based study they could be expected to be equally distributed across the catchment areas. ${ }^{19}$
The problem of selection bias is pertinent to the comparison of birth outcomes in different hospitals. In this area based analysis, both medical referrals and self selecting patients were classified as births in the first choice level of care of their community. In Finland, self selection is a problem in some municipalities where two or more maternity units are available within a similar distance. In this analysis these municipalities could not be assigned a primary choice hospital and were thus treated separately. In the pooled catchment areas self selection was probably the cause of $7 \%$ of women not giving birth in tertiary care hospitals where that level was the first choice for birth care in their municipality. The proportion of women self selecting to other levels of care cannot be defined for catchment areas of levels 1 and 2 .

The rate of tertiary care births varied from $92 \%-7 \%$ across the areas, yet crude and birthweight specific perinatal mortality rates were very similar in the areas. This shows a true egalitarian situation between the areas in terms of safety despite the differences in the organisation of birth care. Similarly, in The Netherlands no relation could be shown between the regional percentage of hospital deliveries and the regional perinatal mortality rates. ${ }^{20}$ Canada, provinces with high and low rates of deliveries in small hospitals had similar patterns of perinatal mortality rates. ${ }^{7}$

In conclusion, this study concurs with others and indicates that "safety" cannot be used as a basis for centralising birth care in large level 3 facilities. In this regionalised system areas served by small units had survival and morbidity rates equal to areas served by large university hospitals, from the very low birthweight to normal birthweight infants. The importance of regionalisation for the safety of small hospitals is pertinent: in a study describing a non-regionalised system where adequate referral was lacking, higher mortality was shown for high risk normal birthweight babies in primary level than in tertiary level care. ${ }^{9}$

When safety alone cannot be used as the determining factor in deciding whether to centralise, other factors such as economy and preferences of the families are important. In the economic analysis not only the direct costs of care but also the expenses (monetary and other costs) to the family should be considered. The care should not only be safe and economical but also convenient for the family. So far the preferences of families have been poorly examined and seldom implemented into birth care policy.

1 Campbell R, MacFarlane A. Where to be born? The debate and the evidence. Oxford: National Perinatal Epidemiand the evidence.

2 Paneth N, Kiely JL, Wallenstein S, et al. Newborn intensive care and neonatal mortality in low birth weigh .

3 Gortmaker S, Sobol A, Clark C, et al. The survival of very low birth weight babies by level of hospital of birth: population study of perinatal systems of four states. $\mathrm{Am}$ Obstet Gynecol 1985;152:517-24.

4 Hemminki E. Perinatal mortality distributed by type of hospital in the central hospital district of Helsinki, Fin land. Scand F Soc Med 1985;13:113-18.

5 Lumley J. The safety of small maternity hospitals in Vic- 
toria 1982-84. Community Health Studies 1988;XII:38693.

6 Rosenblatt RA, Reinken J, Shoemack P. Is obstetrics safe in small hospitals? Evidence from New Zealand's regionalised perinatal system. Lancet 1985;ii:429-32.

7 Fallis G, Dunn E Hilditch J. Small hospital obstetrics, is small beautiful? The fournal of Rural Health 1988;4:10117 .

8 Campbell R, MacFarlane A. Place of delivery: a review. Br F Obstet Gynaecol 1986;93:675-83.

9 Berg CJ, Druschel CM, McGarthy BJ, LaVoie M, Floyd RL. Neonatal mortality in normal birth weight babies: does the level of hospital care make a difference? $A m \mathcal{f}$ does the level of hospital care

10 Albers LL, Savitz DA. Hospital setting for birth and use of medical procedures in low risk women. $\mathcal{F}$ Nurs Midwifery

11 Hemminki E, Malin M, Kojo-Austin H. Prenatal care in Finland: from primary to tertiary health care? Int $\mathscr{f}$ Health Serv 1990;20:221-32.

12 Hemminki E. Obstetric practice in Finland, 1950-1980. Changes in technology and its relation to health. Med Care 1983;21:1131-43.

13 Hemminki E, Teperi J, Tuominen K. Need for and influ- ence of feedback from the Finnish birth register to dataproviders. Quality Assurance in Health Care 1992;4:133-

14 Hemminki E, Meriläinen J, Malin M, Rahkonen O, Teperi J. Mother's education and perinatal problems. A nationwide study in Finland. Int 7 Epidemiol 1992;21:720-4.

15 Statistics Finland. Statistical yearbook of Finland 1992 VaPK, Helsinki 1992.

16 Stephenson PA. International differences in the use of obstetrical interventions. Copenhagen: WHO Regional office for Europe, 1992. Eur/ICP/MCH 112.

17 Manderbacka K, Meriläinen J, Hemminki E, Rahkamo O, Teperi J. Marital status as a predictor of perinatal outcome. fournal of Marriage and the Family 1992;54:508-515.

18 Teperi J. A multi-method approach to the assessment of data quality in the Finnish Medical Birth Registry. quality in the Finnish Medical Birth

19 Eksmyr R. Two geographically defined populations with different organization of medical care. Cause specific analysis of early neonatal deaths. Acta Paediatr Scand 1986 75:10-16.

20 Treffers PE, Laan R. Regional perinatal mortality and regional hospitalization at delivery in the Netherlands. $\mathrm{Br} f$ Obstet Gynaecol 1986;93:690-93. 